\title{
BRIEF
}

\section{Student Engagement Effect of Team-Based Learning in A College of Pharmacy: A Qualitative Case Study}

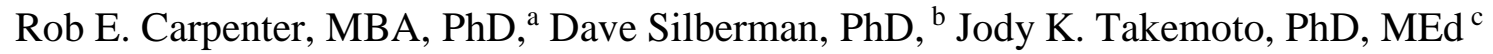 \\ ${ }^{a}$ The University of Texas at Tyler, Soules College of Business, Tyler, Texas \\ ${ }^{\mathrm{b}}$ Boston University, Boston, Massachusetts \\ ${ }^{\mathrm{c}}$ The University of Texas at Tyler, Ben and Maytee Fisch College of Pharmacy, Tyler, Texas
}

Corresponding Author: Rob E. Carpenter, The University of Texas at Tyler, Soules College of Business, 3900 University Blvd, Tyler, Texas 75799. Tel: 903-805-9955. Email: rec@rlventures.com

Submitted January 30, 2021; accepted August 26, 2021; ePublished September 2021

Objective. The objective of this research was to expand the perspective of student engagement by qualitatively examining how student pharmacists experienced engagement using team-based learning (TBL) pedagogy.

Methods. A qualitative case study was adopted. Data were obtained from a purposeful and convenience sampling of student pharmacists $(n=14)$ through semi-structured interviews. Initial data analysis identified common themes, followed by oriented coding of the common themes to the focal concepts of predetermined engagement components.

Results. Seven common themes arose from this research: 1) accountability; 2) communication; 3) conflict; 4) learning; 5) preparation; 6) purpose; and 7) teamwork. Results indicated student pharmacists in TBL pedagogy primarily experience student engagement through a relate (41\%) component, followed by donate $(32 \%)$ and create $(27 \%)$.

Conclusion. Findings in this study are consistent with other research that implicates TBL pedagogy, at least in part, a conduit for building student pharmacists' engagement skills. The novelty of this research is that it characterizes the subjective construal underlying engagement in TBL by recognizing the relate component most important for developing student pharmacists' engagement skills. ${ }^{1}$

Keywords: engagement theory, student engagement, TBL

\section{INTRODUCTION}

Integration in various health care settings prompts pharmacy schools to seek better ways to prepare students to actively engage the practice of pharmacy. However, the majority of U.S.-based pharmacy schools ${ }^{2}$ emphasize passive didactics, not active learning. ${ }^{3}$ Active learning has demonstrated improvement in student engagement, achievement, and lower attrition. ${ }^{4,5}$ Active learning is encouraged by the Accreditation Council for Pharmacy Education; introducing a noteworthy challenge for pharmacy schools to incorporate learning experiences promoting engagement skills. Despite significant student engagement research, much remains unknown on the interaction between engagement and learning. ${ }^{6}$ Certain assumptions about how students process, store, and apply information about their social interactions position engagement a psychological state of social cognition. ${ }^{7,8}$ There is a need to better understand the subjective construal underlying this psychological state in active learning environments.

Team-based learning (TBL) is an active learning pedagogy that follows a prescriptive sequence and is embraced for actively stimulating student engagement. ${ }^{9,10} \mathrm{TBL}$ also promotes other outcomes important to practicing pharmacists such as improved communication, critical thinking, and effective preparation to manage clinical situations with increased confidence. ${ }^{10-13}$ Engagement is a key component to TBL's success. ${ }^{14}$ Social characteristics of how student engagement manifests in TBL is less understood. The purpose of this study was to characterize the student engagement experience in a pharmacy program primarily utilizing TBL. To do this, Kearsley and Shneiderman's view on student engagement was employed as the basis of study given its potential to highlight deeper construal insights on student engagement. ${ }^{1}$ Kearsley and Shneiderman characterize engaged students as active participants in their learning through components of relate, create, and donate. ${ }^{1}$ Each component reveals how individuals perceive, comprehend, and interpret their environment. Relate emphasizes learners drawing team support and trusting each other through communication and assistance to accomplish tasks. Create implies making learning an activity that has innovative value. Donate stresses valuable contribution to society to improve one's own humane quality as a byproduct of learning. It is hypothesized that Kearsley and Shneiderman's engagement components reveal a social cognition perspective of engagement that remains unexamined in TBL. 


\section{METHODS}

A qualitative case study was adopted to obtain rich and naturalistic data. ${ }^{15}$ Kearsley and Shneiderman's components of engagement (relate, create, donate) was the basis of this investigation of participant experiences' in TBL in a college of pharmacy (COP). Inclusion criteria consisted of those 18+ years of age enrolled at the COP. This study was approved by the Institutional Review Board at The University of Texas at Tyler.

Individual recorded semi-structured interviews consisted of peer-reviewed open-ended and follow-up questions until data saturation was reached. ${ }^{16-18}$ Open-ended questions included background information, school experiences, and the participant's TBL experience. Follow-up questions extracted details about responses related to student engagement and components of engagement. Deidentified codes assigned to each interviewee were used upon transcription. Each transcript was reviewed independently by two of the authors for accuracy of the data for analysis. ${ }^{19}$

First, an inductive coding approach was used to identify underlying ideas and assumptions to common themes. Subsequently, a deductive coding approach was used to classify each common theme as an engagement component of relate, create, or donate (Figure 1) ${ }^{20}$ An expert coder independently classified the data for verification. Remaining faithful to the theory, intersubjectivity led to supplementary category classifications until agreement.

\section{RESULTS}

Fourteen participants were selected using purposeful and convenience sampling. ${ }^{16}$ Demographics were collected because convenience sampling is not random (Table 1). This form of sampling can produce a sampling bias in which some members of the population are less likely to be included than others.

Seven common themes were identified through inductive analysis: accountability, communication, conflict, learning, preparation, purpose, and teamwork. Agreement between the researchers' independent coding was met (mean $92 \%$, range 87-98\%). Deductive analysis classified common themes as characteristics of Kearsley and Shneiderman's engagement components relate $(41 \%)$, create $(27 \%)$, and donate $(32 \%)$. Relate components emphasized team-based efforts involving communication, management, and social skills. Create components emphasized elements that made learning creative or purposeful. Donate components emphasized elements that stressed the value of making a useful contribution while learning (Table 2). Researchers enlisted an expert coder to independently classify common themes until meeting agreement for classifications to remain faithful to the theory. ${ }^{21}$

\section{DISCUSSION}

This study builds upon the literature by exploring Kearsley and Shneiderman's engagement components to characterize aspects of social cognition important to the psychological state of student engagement in TBL. Data revealed that students primarily characterize engagement through the relate component. To relate to a social setting is an important construal on the subjective reality of personal significance. ${ }^{22,23}$ TBL encouraged discourse building opportunities for students to relate to their group during discussion in the readiness assurance process (RAP). TBL provided students the opportunity to relate in team application exercises by encouraging participation through idea assessment, hypotheses testing, and collaborative think. Requiring teams to make and defend a specific choice through collective knowledge and skill on the team exercises encouraged team-building. ${ }^{10}$ Exercises provided students opportunities for self-comparison; commonly occurring when personal significance is uncertain. ${ }^{24}$ Deductive analysis classified common themes communication, conflict, and teamwork as positive TBL experiences that facilitated students' to relate to their cohorts.

\section{Relate}

Deductive analysis of communication as a relate component involved suggestion of TBL facilitating opportunities to trust peers through communication and task accomplishment. Data suggested that TBL provided students the opportunity to practice social skills through communication, building confidence to transfer these skills to their future profession. Communication skills are imperative for pharmacists to interact with health care providers and patients to achieve desired outcomes, thus conflict management is a requisite skill for pharmacists. Conflict can occur when engaging with others. Opportunities to practice managing and resolving conflict are facilitated in TBL. ${ }^{10}$ The TBL environment created a safe place for negotiation, disagreement, and resolution translating to growth, curiosity, and intellectual development.

Teamwork was recognized as a structured setting of participation, where achievement was a measure of collective intrapersonal engagement that improved problem solving and collaborative discourse. ${ }^{25,26} \mathrm{TBL}$ enhances engagement by placing student teams at the center of learning. ${ }^{27}$ Teamwork is strengthened by the interpersonal salience of the engaged individuals in the group and can act as the agent of group success. Keeping groups together long enough to develop collaborative discourse and effective group interaction is imperative. ${ }^{28}$ Inherent to collaborative discourse or effective 
group interaction is the social need to cognitively relate to individual team members. Thus, teamwork was deductively classified as a relate component of engagement. TBL provided students agency to relate through communication, conflict, and teamwork and engendered significant construal for the psychological state of engagement.

\section{Create}

Common themes learning and preparation were classified as create components of engagement. Learning requires creating knowledge, thus deductively classified as a create component. ${ }^{29}$ Learning was defined as the advancement of individual learning through a team-based context. Active learning leads to a greater degree of comprehension and retention. ${ }^{30}$ Participants identified TBL as a facilitator of individual learning. TBL interactions are described as a catalyst for individual learning due to its design and nature of teaming as a resource for missed and/or unclear concepts.

TBL is centered upon preparation. Preparation requires dedicated time to review materials prior to class to successfully participate in TBL. ${ }^{10}$. The coding for preparation included mention of dedicated time and material review needed to successfully participate in the TBL session. Students are accountable to their teammates through team quizzes administered on preparation materials [readiness assessment tests (RATs)], allowing the team to monitor individual team members' degree of preparedness. Compared with traditional lectures, TBL enhances student engagement through required preparation. ${ }^{31}$ Most respondents commented that TBL required greater preparation time than traditional lecture experiences. Participants perceived preparation to be productive for the learning process. Individual preparation was critical to the success of TBL. Routine practice of preparation promotes students as "collaborative learners in the classroom". ${ }^{10 p 10}$

The create component of engagement emphasized elements that make learning a creative pursuit along with elements that can be considered purposeful activity. ${ }^{1}$ TBL purposefully obfuscates pre-existing social groupings in favor of team-grouping methods designed to create emergent team performance cohesion, requiring creative and purposeful team efforts. This type of learning improved team cooperation and the coordinated abilities of the students. Notwithstanding, the least perceived engagement component was create; likely because leaning and preparation are individual pursuits.

\section{Donate}

The engagement component of donate was less significant than relate but more significant than create. Data revealed many participants entered pharmacy to give something of themself to humanity. The desire to make contributions is often intrinsically motivated. Donate emphasized elements stressing the value of making a useful contribution while learning. ${ }^{1}$ TBL reinforced intrinsic motivation with extrinsic opportunities to engage through contribution. Students who were sociality motivated to contribute to a team environment were more likely to demonstrate an engaged giving behavior. The act of giving is an exercise in forethought - motivated individuals giving in anticipatory proactive ways. ${ }^{32}$ For example, high levels of student engagement is predictive of alumni donations and volunteer activity. ${ }^{33}$

The common themes of purpose and accountability were proxies of the donate component. Students who are knowingly purposive and accountable to their team can anticipate likely consequences of prospective actions. This engendered students to set individual and team goals for desired outcomes. Participants described positive TBL experiences when an outcome reinforced or validated their decision to become a pharmacist. It may be presupposed to classify purpose as a create component of engagement given an element of create is purposeful activity. However, the latent content of purpose described by the respondents shifted the focus to the meaning underlying the message of purpose. Thus, purpose was deductively classified as a donate component of engagement because inherent within the psychosocial state of purpose toward others is an element of donation. ${ }^{34}$

Peer accountability is important to team success. Individual accountability was reinforced through the RAP and periodic formal peer evaluation, promoting student accountability to the team and team accountability. ${ }^{9}$ Stein and colleagues identified that teams were consistent in giving the least involved team member lower scores. ${ }^{35}$ Participants reported doing more to prepare for TBL classes compared to passive lecture classes in effort to do well on the RAT for team benefit. Whereas traditional passive lectures are absent a level of intimacy, TBL encouraged active participation encountering teammate differences, which students associated with accountability. This conditioning is the foundation for student accountability to the populations they will serve as pharmacists. In the deductive coding schema, accountability was considered as mentions of TBL increasing accountability and promoting learning. Accountability was classified as a donate component as any psychological state of internal accountability incorporates giving behavior. ${ }^{36}$

TBL was a conduit for engaged learning through the components of relate, create, and donate. The causal agency for these engagement characteristics resides in self-regulatory mechanisms implicit to one's own social capacity. Future research is needed to examine the complex role that cognitive processes play between social interactions in TBL, the transferability of engagement skills to the profession, and how components of engagement provide opportunities to 
improve pharmacy practice.

\section{Limitations}

This research has inherent case study limitation of generalizability. Limitations of this study included a small sample size which may narrow the findings despite data saturation. ${ }^{37}$ The sample size was inclusive to all class years though unequally represented with the same percentages of representative demographics. Results relied upon honest, unbiased, and accurate participant perspective and unbiased research analysis and interpretation. ${ }^{38}$ While participants were from different years in pharmacy, the tenants of TBL were adhered to therefore unlikely a contributing variable.

\section{CONCLUSION}

Common themes were consistent with previous research indicating that TBL serves as a conduit for building student pharmacists' engagement skills. The novelty in this research lies in extending student engagement as a subjective social cognition experience to characterize construal underlying student engagement in TBL. Specifically, TBL should be considered a primary conduit for student engagement through a relate component that emphasizes learners drawing support from trusting peers through communication and assistance to accomplish tasks.

\section{ACKNOWLEDGMENTS}

The authors thank the student participants and Dr. Rochell McWhorter for expert coding.

\section{REFERENCE}

1. Kearsley G. Engagement theory: a framework for technology-based teaching and learning. Educ Tech. 1998;38(5):20-23.

2. American Association of Colleges of Pharmacy. Academic Pharmacy's Vital Statistics. https://www.aacp.org/article/academic-pharmacys-vital-statistics. Published 2020. Accessed December 28, 2020.

3. Johnson HA, Barrett L. Your teaching strategy matters: how engagement impacts application in health information literacy instruction. J Med Libr Assoc. 2017;105(1):44-48. doi:10.5195/jmla.2017.8

4. Glanville JL, Wildhagen T. The measurement of school engagement. Educ Psychol Meas. 2007;67(6):1019-1041. doi:10.1177/0013164406299126

5. Graffam B. Active learning in medical education: strategies for beginning implementation. Med Teach. 2007;29(1):38-42. doi:10.1080/01421590601176398

6. Axelson RD, Flick A. Defining student engagement. Change: The Magazine of Higher Learning. 2010;43(1):38-43. doi:10.1080/00091383.2011.533096

7. Forgas JP. Feeling and thinking: The role of affect in social cognition. Cambridge University Press; 2001.

8. Parker SK, Griffin MA. Understanding active psychological states: embedding engagement in a wider nomological net and closer attention to performance. Euro J Work Org Psychol. 2011;20(1):60-67. doi.org/10.1080/1359432X.2010.532869

9. Burgess A, Kalman E, Haq I, Leaver A, Roberts C, Bleasel J. Interprofessional team-based learning (TBL): how do students engage? BMC Med Educ. 2020;20(1):118. doi:10.1186/s12909-020-02024-5

10. Ofstad W, Brunner LJ. Team-based learning in pharmacy education. Am J Pharm Educ. 2013;77(4):70. doi:10.5688/ajpe 77470

11. Silberman D, Carpenter R, Takemoto JK, Coyne L. The impact of team-based learning on the critical thinking skills of pharmacy students. Curr Pharm Teach Learn. 2021;13(2):116-121. doi:10.1016/j.cptl.2020.09.008

12. Koles P, Nelson S, Stolfi A, Parmelee D, Destephen D. Active learning in a Year 2 pathology curriculum. Med Educ. 2005;39(10):1045-1055. doi:10.1111/j.1365-2929.2005.02248.x

13. Ameer L, Maclure K, Tonna A, Stewart D. An initial exploration of the perceptions of preparedness to practice among Saudi Arabian trained hospital pharmacists. Pharm Pract (Granada). 2018;16(2):1192. doi:10.18549/PharmPract.2018.02.1192

14. Searle NS, Haidet P, Kelly PA, Schneider VF, Seidel CL, Richards BF. TBL in medical education: initial experiences at ten institutions. Acad Med 2003;78 (10 Suppl.):S55-58.

15. Stake RE. The Art of Case Study Research. Thousand Oaks: Sage Publications; 1995.

16. Flick U. Designing Qualitative Research (Qualitative Research Kit). Sage; 2018.

17. Anderson V. Criteria for evaluating qualitative research. Hum Resource Dev Q. 2017;28(2):125-133. doi:10.1002/hrdq. 21282

18. Creswell JW. Research Design: Qualitative, Quantitative and Mixed Methods Approaches. Sage; 2017. 
19. Potter WJ, Levine-Donnerstein D. Rethinking validity and reliability in content analysis. Journal of Applied Communication Research. 1999;27(3):258-284. doi:10.1080/00909889909365539

20. Mayring P. Qualitative Content Analysis. In: A Companion to Qualitative Research. First. SAGE Publications Ltd; 2004.

21. Bandura A. Social cognitive theory of self-regulation. Organ Behav Hum Decis Process. 1991;50(2):248-287. doi:10.1016/0749-5978(91)90022-L

22. Lewin K. Frontiers in group dynamics. Human Relations. 1947;1(2):143-153. doi:10.1177/001872674700100201

23. Cheng RW, Lam S. Self-construal and social comparison effects. Br J Educ Psychol. 2007;77(Pt 1):197-211. doi:10.1348/000709905X72795

24. Van Meter P, Stevens RJ. The role of theory in the study of peer collaboration. The Journal of Experimental Education. 2000;69(1):113-127. doi:10.1080/00220970009600652

25. Sweet M, Michaelsen LK. How group dynamics research can inform the theory and practice of postsecondary small group learning. Educ Psychol Rev. 2007;19(1):31-47. doi:10.1007/s10648-006-9035-y

26. Birmingham C, McCord M. Group process research: implications for using learning groups. In: Michaelsen LK, Knight AB, Fink LD, eds. Team-Based Learning: A Transformative Use of Small Groups in College Teaching. 1st ed. Stylus Publishing; 2004:73-93.

27. Remington TL, Bleske BE, Bartholomew T, et al. Qualitative analysis of student perceptions comparing team-based learning and traditional lecture in a pharmacotherapeutics course. Am J Pharm Educ. 2017;81(3):55. doi:10.5688/ajpe81355

28. Green A, de Bodisco C. Using team-based learning in discussion and writing classes. International Review of Economics Education. 2020;35:100195. doi:10.1016/j.iree.2020.100195

29. Savin-Baden M. Learning Spaces: Creating Opportunities for Knowledge Creation in Academic Life. 1st ed. Open University Press; 2007.

30. Malik S. Active lecturing: an effective approach for large classes. In Proceedings International Conference on Social Science and Humanity; 2011: 214-217.

31. Allen RE, Copeland J, Franks AS, et al. Team-based learning in US colleges and schools of pharmacy. Am J Pharm Educ. 2013;77(6):115. doi:10.5688/ajpe776115

32. Bandura A. Anticipatory and self-reactive mechanisms. In: Vol 38. ; 1991.

http://www.uky.edu/ eushe2/BanduraPubs/Bandura1991Nebraska.pdf. Accessed May 29, 2021.

33. Weerts DJ, Ronca JM. Using classification trees to predict alumni giving for higher education. Education Economics. 2009;17(1):95-122. doi:10.1080/09645290801976985

34. McIntyre P, Barnett MA, Harris RJ. Psychological factors influencing decisions to donate organs. ACR North American Advances. 1987.

35. Stein RE, Colyer CJ, Manning J. Student accountability in team-based learning classes. Teach Sociol. 2016;44(1):28-38. doi:10.1177/0092055X15603429

36. Dubnick MJ, Yang K, Menzel DC. The pursuit of accountability: promise, problems, and prospects. Political Science Scholarship. January 2011.

37. Crouch M, McKenzie H. The logic of small samples in interview-based qualitative research. Social Science Information. 2006;45(4):483-499. doi:10.1177/0539018406069584

38. Wynder EL. Investigator bias and interviewer bias: the problem of reporting systematic error in epidemiology. $J$ Clin Epidemiol. 1994;47(8):825-827. doi:10.1016/0895-4356(94)90184-8

39. Hazel SJ, Heberle N, McEwen M-M, Adams K. Team-based learning increases active engagement and enhances development of teamwork and communication skills in a first-year course for veterinary and animal science undergraduates. $J$ Vet Med Educ. 2013;40(4):333-341. doi:10.3138/jvme.0213-034R1

40. Neumeyer X, Santos S. The effect of team conflict on teamwork performance: An engineering education perspective. Int J Eng Educ. 2020;36:502-509.

41. Gallegos PJ, Peeters JM. A measure of teamwork perceptions for team-based learning. Currents in Pharmacy Teaching and Learning. 2011;3(1):30-35. doi:10.1016/j.cptl.2010.10.004

42. Savickas ML. The theory and practice of career construction. In: Brown SD, Lent RW, eds. Career development and counseling: Putting theory and research to work. John Wiley \& Sons, Inc.; 2005:42-70. 
Figure 1. Methodology process.

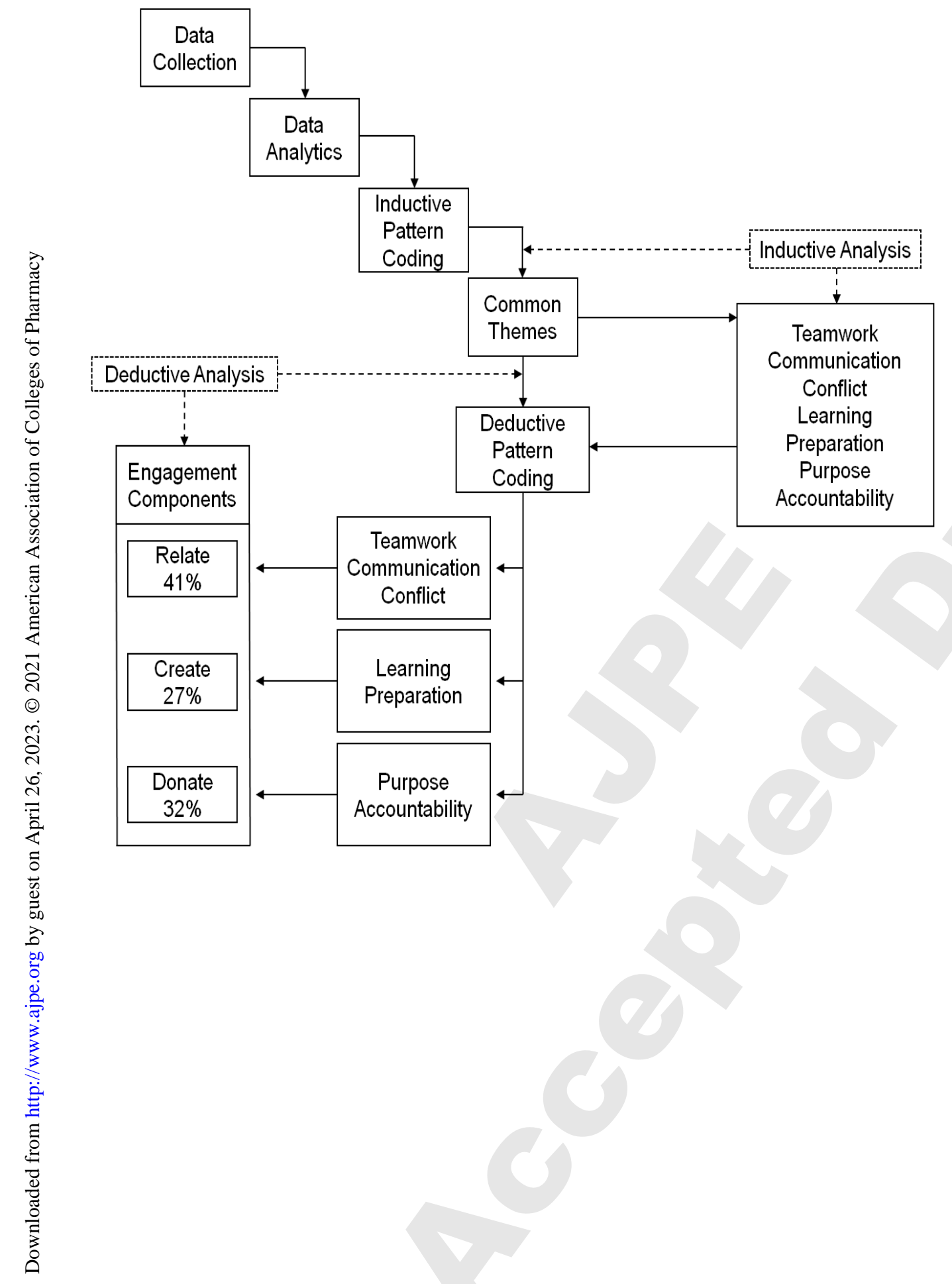


Table 1. Demographic Characteristics $(n=14)$

\begin{tabular}{lcc}
\hline CHARACTERISTIC & & \\
\hline Age (years) & $\begin{array}{c}\text { (Mean) } \\
\text { (Range })\end{array}$ & $23-38$ \\
Class Status & (Year in program) & $($ Range $)$ \\
& $2^{\text {nd }}$ & $1^{\text {st }}-4^{\text {th }}$ \\
& & \\
Gender Distribution & $(\boldsymbol{n})$ & $(\boldsymbol{\%})$ \\
Male & 4 & 28.6 \\
Female & 10 & 71.4 \\
Ethnicity & & \\
White & 6 & 42.8 \\
Black/African American & 5 & 35.8 \\
Hispanic & 2 & 14.3 \\
Middle Eastern & 1 & 7.1 \\
Degree (prior to pharmacy school) & & \\
Associate of Science & 1 & 7.1 \\
Associate of Arts & 1 & 7.1 \\
Bachelor of Science & 5 & 35.8 \\
None & 7 & 50.0 \\
English Language Learner & 3 & 21.4 \\
Yes & 11 & 78.6 \\
No & & \\
\hline
\end{tabular}


Table 2. Common Themes Identified with Descriptions, Support Reference(s), and Engagement Components

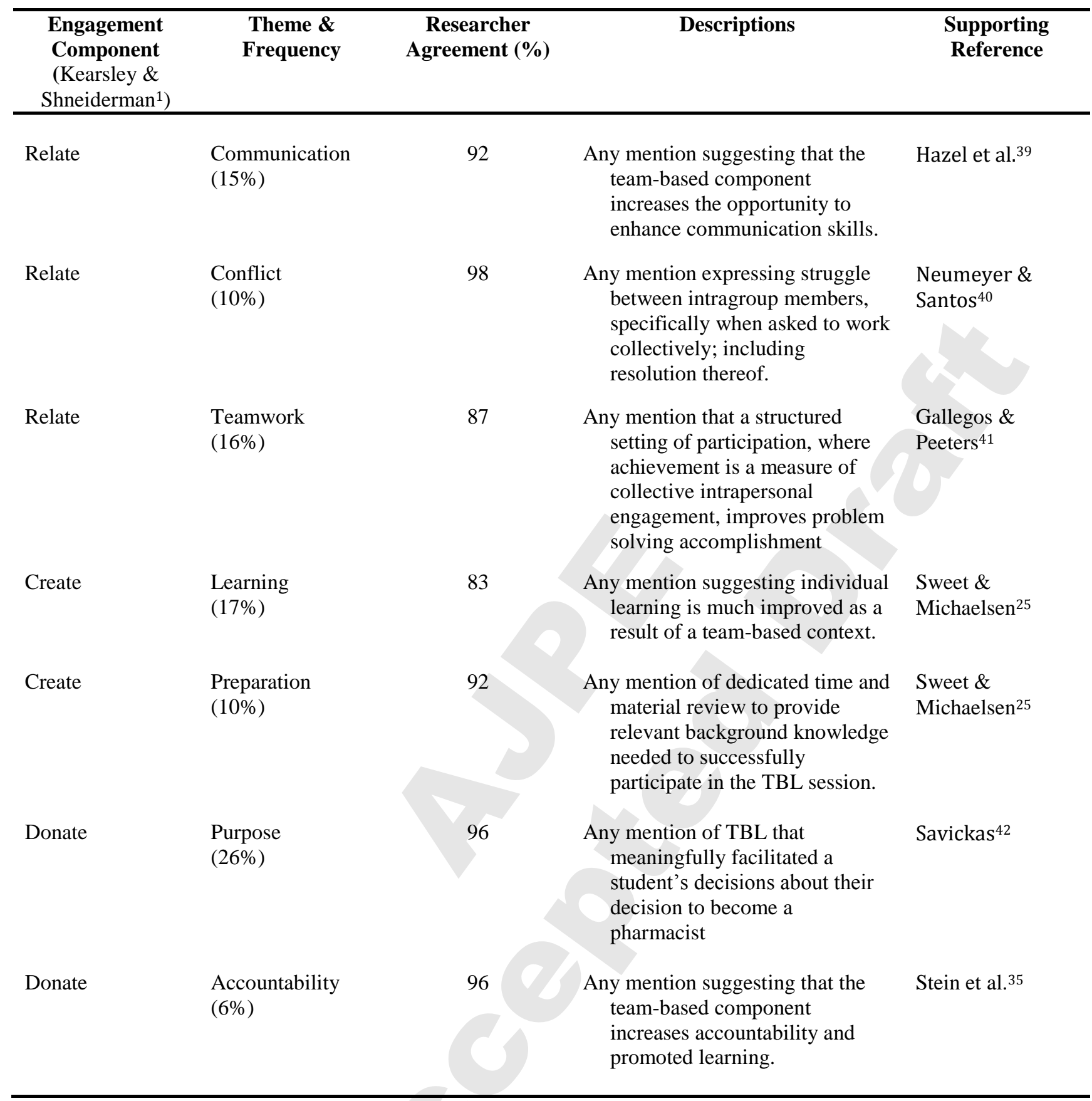

